\title{
Alpha-Lipoic Acid Alleviates High-Glucose Suppressed Osteogenic Differentiation of MC3T3-E1 Cells via Antioxidant Effect and PI3K/Akt Signaling Pathway
}

\author{
Kai Dong ${ }^{a}$ Pengjie Hao ${ }^{a}$ Sheng Xua Shutai Liu ${ }^{a}$ Wenjuan Zhou ${ }^{a}$ Xilong Yue \\ Xiaohui Rausch-FAN ${ }^{b}$ Zhonghao Liu ${ }^{a}$ \\ aDepartment of Dental Implantology, Yantai Stomatological Hospital, Shandong, P.R. China; \\ bDepartment of Stomatology, Medical University of Vienna, Vienna, Austria
}

\section{Key Words}

Alpha-lipoic acid - Osteoblast - ROS - Oxidative stress - Hyperglycemia - Diabetes • Osseointegration

\begin{abstract}
Background/Aims: Patients with diabetes mellitus have a higher risk of dental implant failure. One major cause is high-glucose induced oxidative stress. Alpha-lipoic acid (ALA), a naturally occurring compound and dietary supplement, has been established as a potent antioxidant that is a strong scavenger of free radicals. However, few studies have yet investigated the effect of ALA on osteogenic differentiation of osteoblasts cultured with high glucose medium. The aim of this study is to investigate the effects of ALA on the osteoblastic differentiation in MC3T3-E1 cells under high glucose condition. Methods: MC3T3-E1 cells were divided into 4 groups including normal glucose $(5.5 \mathrm{mM})$ group (control), high glucose $(25.5 \mathrm{mM})$ group, high glucose + $0.1 \mathrm{mM}$ ALA group, and high glucose + $0.2 \mathrm{mM}$ ALA group. The proliferation, osteogenic differentiation and mineralization of cells were evaluated by MTT assay, alkaline phosphatase (ALP) activity assay, alizarin red staining and real time-polymerase chain reaction. High-glucose induced oxidative damage was also assessed by the production of reactive oxygen species (ROS) and superoxide dismutase (SOD). Western blots were performed to examine the role of PI3K/Akt pathway. Results: The proliferation, osteogenic differentiation and mineralization of MC3T3-E1 cells were significantly decreased by the ROS induced by high-glucose. All observed oxidative damage and osteogenic dysfunction induced were inhibited by ALA. Moreover, the PI3K/Akt pathway was activated by ALA. Conclusions: We demonstrate that ALA may attenuate high-glucose mediated MC3T3-E1 cells dysfunction through antioxidant effect and modulation of PI3K/Akt pathway.
\end{abstract}




\section{Cellular Physiology Cell Physiol Biochem 2017;42:1897-1906 \\ \begin{tabular}{l|l} 
DOI: 10.1159/000479605 & and Biochemistry \\
Published onlne: August 03, 2017 & $\begin{array}{l}\text { O 2017 The Author(s). Published by S. Karger AG, Basel } \\
\text { www.karger.com/cpb }\end{array}$ \\
\cline { 2 - 3 }
\end{tabular} \\ Dong et al.: ALA Promotes Osteogenesis of MC3T3-E1 Cells}

\section{Introduction}

The application of implant therapy in dentistry has offered viable solutions for the rehabilitation of edentulism and has been widely used as an attractive substitute to the traditional fixed/removable prosthesis [1]. The success of titanium implants is directly related to how quickly and completely the surrounding tissues grow in close apposition to the implant, via the process of osseointegration as defined by direct bone-to-implant contact and bone tissue growth surrounding the implant. The process of osseointegration must be initiated when the implant is initially placed into a prepared surgical site and then maintained. Moreover, the process is largely dependent on the proliferation and differentiation of osteoblasts [2, 3]. Systematic reviews have reported high clinical success rates for implantsupported restorations in generally healthy individuals $[4,5]$.

However, many systemic diseases such as osteoporosis, diabetes, and autoimmune diseases may interfere with the implant osseointegration [6]. Researches have shown that diabetes caused a higher failure rate of implants and poorer bone-implant integration [7, 8]. Type 2 diabetes mellitus, accounts for approximately $90-95 \%$ of the patients with the disease, is a metabolic disorder characterized by hyperglycemia resulting from peripheral insulin resistance with relative insulin deficiency [9].

Chronic hyperglycemia, pathognomonic of diabetes mellitus, is known to have an adverse impact on bone healing process, such as vascularization, clot formation, and bone matrix synthesis. For those who fail to control their glucose levels, the attendant uncontrolled hyperglycemia is considered a contra-indication for dental implant placement [10]. Studies have shown that hyperglycemia leads to an increased production of reactive oxygen species (ROS) in osteoblasts, which subsequently disrupts the cellular oxidant-antioxidant balance $[11,12]$. Hyperglycemia-induced ROS have been proposed to be generated via several mechanisms including formation of increased advanced glycation end-products (AGEs), increased polyol pathway flux, activation of protein kinase $\mathrm{C}$ isoforms, glucose autoxidation, and mitochondrial overproduction of superoxide under diabetic conditions. Other circulating factors that are elevated in diabetes, such as free fatty acids and leptin, also contribute to increased ROS generation [13].

Alpha-lipoic acid (ALA), also called thioctic acid, is chemically named 1,2-dithiolane3-pentanoic acid, which can be detected naturally in fruits, vegetables, and synthesized in animals and humans. ALA is a naturally occurring essential coenzyme in mitochondrial multienzyme complexes and acts as a key player in mitochondrial energy production [14]. Various experimental models have demonstrated that ALA, as a universal antioxidant, can effectively inhibit pathologies in which reactive oxygen species (ROS) have been implicated, such as ischemia-reperfusion injury, radiation injury and diabetes induced oral implant failure $[15,16]$. Furthermore, ALA has received much attention because of its effects on osteoblasts and osteoclasts due to its strong anti-oxidative activity [17].

To our limited knowledge, there have been few studies indicating the effects of ALA on the osteoblastic differentiation of osteoblasts under high glucose condition. In addition, MC3T3-E1 osteoblast-like cell line culture system represents a very useful model for studying the process of osteoblast function [18]. Therefore, the aim of our study was to observe the protective effects of ALA against high glucose-induced ROS production using osteoblast-like MC3T3-E1 cells, and explore the regulatory mechanism of PI3K/Akt signaling pathway, thus providing theoretical basis for the clinical applications of ALA.

\section{Materials and Methods}

\section{Cell culture}

MC3T3-E1 cells (purchased from the Cell Bank of the Chinese Academy of Sciences) were cultured in $\alpha$-MEM (HyClone, Logan, UT, USA) mineralizing medium containing $10 \%$ fetal bovine serum, $1 \%$ penicillin-streptomycin, $100 \mathrm{mg} / \mathrm{ml}$ ascorbic acid, $10 \mathrm{mM}$ b-glycerophosphate phosphate and $1 \times 10^{-8} \mathrm{M}$ 


\section{Cellular Physiology Cell Physiol Biochem 2017;42:1897-1906 \begin{tabular}{l|l|l} 
and Biochemistry Published online: August 03, 2017 & $\begin{array}{l}\text { C) } 2017 \text { The Author(s). Published by S. Karger AG, Basel } \\
\text { www.karger.com/cpb }\end{array}$ \\
\hline
\end{tabular}}

Dong et al.: ALA Promotes Osteogenesis of MC3T3-E1 Cells

dexamethasone in $5 \% \mathrm{CO} 2$ at $37^{\circ} \mathrm{C}$. The cells were subsequently divided into 4 experimental groups [19, 20]: (1) the control group: normal glucose (5.5 mM) $\alpha$-MEM alone (NG), (2) the high glucose group: high glucose (25.5 mM) $\alpha$-MEM alone (HG), (3) the $0.1 \mathrm{mM}$ ALA group: high glucose $\alpha$-MEM + 0.1 mM ALA (HG+) and (4) the 0.2 mM ALA group: high glucose $\alpha$-MEM + 0.2 mM ALA (HG++).

\section{Cell viability assay}

The MTT (3-(4, 5-dimethylthiazol-2-yl)-2,5-diphenyltetrazolium bromide) assay was used to estimate the proliferation of osteoblasts under high glucose conditions. Briefly, the cells were plated in 96-well plates at a density of $1 \times 10^{4}$ cells/well into 5 repeat wells. After being cultured for $24 \mathrm{~h}$, the cells were serumstarved overnight in $\alpha$-MEM with $0.5 \%$ fetal bovine serum and then replaced with $4 \%$ serum medium containing normal $(5.5 \mathrm{mM})$ or high levels of glucose $(25.5 \mathrm{mM})$ and treated with different concentrations of ALA $(0.1,0.2 \mathrm{mM})$ for $3,7,10$ and 14 days. The absorbance values were read at $570 \mathrm{~nm}$ using an automated microplate reader (Bio-Rad Laboratories, Inc., Hercules, CA, USA).

\section{Measurement of ROS and Superoxide Dismutase (SOD) production}

The cells were plated in 24-well plates at a density of $1 \times 10^{5}$ cells/well into 3 repeat wells. After the cells had attached, the medium was replaced with new medium containing 4\% FBS and normal (5.5 mM) or high $(25.5 \mathrm{mM})$ amounts of glucose, as well as with or without the various concentrations of ALA (0.1, $0.2 \mathrm{mM}$ ) for $72 \mathrm{~h}$. The level of ROS was tested using the fluorescent probe, 2,7-dichlorofluorescein diacetate (DCFH-DA) (Beyotime Institute of Biotechnology, China). Briefly, DCFH-DA, diluted to a final concentration of $10 \mu \mathrm{M}$, was added to the cells, which were then incubated for $20 \mathrm{~min}$ at $37^{\circ} \mathrm{C}$ in the dark. After being washed twice with serum-free medium, the cells were digested for the detection of ROS levels using Synergy HTX microplate reader (BioTek Instruments Inc., Winooski, VT, USA) with the excitation set at $488 \mathrm{~nm}$ and the emission at $525 \mathrm{~nm}$. The SOD activity was detected by Total Superoxide Dismutase Assay Kit with WST-8 (Beyotime Institute of Biotechnology, China) according to the manufacturer's protocols, and the absorbance values were read at $450 \mathrm{~nm}$ using an automated microplate reader (Bio-Rad Laboratories, Inc., Hercules, CA, USA).

\section{Alkaline phosphatase (ALP) assay}

The cells $\left(1 \times 10^{5}\right.$ cells/well) were cultured on 24 -well plates into 3 repeat wells for $24 \mathrm{~h}$, the medium was then changed to new medium with 4\% FBS and normal $(5.5 \mathrm{mM})$ or high $(25.5 \mathrm{mM})$ levels of glucose as well as with or without ALA $(0.1,0.2 \mathrm{mM})$, and cultured for 3, 7, 10 and 14 days. ALP activities in the culture supernatants were determined by measuring hydrolysis of p-nitrophenyl phosphate according to the manufacturer's instructions (Beyotime Institute of Biotechnology, China).

\section{Mineralization assay}

The cells were seeded on 24-well plates at a density of $1 \times 10^{5}$ cells/well into 3 repeat wells with $\alpha$-MEM containing 4\% FBS and normal $(5.5 \mathrm{mM})$ or high $(25.5 \mathrm{mM})$ levels of glucose as well as with or without ALA (0.1, $0.2 \mathrm{mM}$ ). After 21 days, the mineralized nodule formation was detected using Alizarin Red staining. Briefly, cells were rinsed twice with phosphate buffered saline followed by fixation with 4\% Paraformaldehyde for $30 \mathrm{~min}$ at room temperature. Then cells were stained with 2\% Alizarin Red-S (pH 4.2; Sigma, St. Louis, MO, USA) for $20 \mathrm{~min}$ at room temperature and extensively rinsed with distilled water. For quantification, the bound stain was eluted with $10 \%$ (wt/vol) cetylpyridinium chloride and the absorbance of supernatants was measured by the automated microplate reader (Bio-Rad Laboratories, Inc., Hercules, CA, USA) at $570 \mathrm{~nm}$.

\section{Quantitative real-time reverse transcription PCR ( $q R T-P C R)$}

To detect the expression of osteogenic markers including bone morphogenetic protein 2 (BMP-2), collagen type I (COL-I), alkaline phosphatase (ALP), runt-related transcription factor 2 (Runx2), bone sialoprotein (BSP) and osteocalcin (OCN), total RNA was extracted using the Trizol reagent (Takara Bio Inc., Japan) and cDNA was synthesized from $2 \mu \mathrm{g}$ of total RNA using PrimeScript RT Reagent Kit (Takara Bio Inc., Japan) according to the manufacturer"s instructions. Realtime polymerase chain reaction (PCR) was performed using SYBR greenbased PCR master mix kit (Takara Bio Inc., Japan) on a Rotor-Gene 3000 realtime PCR system (Corbett Research Inc., Australian). The PCR conditions were as follows: initial denaturation at 


\section{Cellular Physiology Cell Physiol Biochem 2017;42:1897-1906 \begin{tabular}{l|l|l} 
and Biochemistry & Published online: August 03, 2017 & $\begin{array}{l}\text { (c) } 2017 \text { The Author(s). Published by S. Karger AG, Basel } \\
\text { www.karger.com/cpb }\end{array}$
\end{tabular}}

$95^{\circ} \mathrm{C}$ for 30 sec followed by 40 cycles, each of $95^{\circ} \mathrm{C}$ for $5 \mathrm{sec}$ and $60^{\circ} \mathrm{C}$ for $30 \mathrm{sec}$. Fluorescence signal was monitored at $585 \mathrm{~nm}$ during each extension. The specific primers were synthesized commercially from Sangon Biotech Inc (China) and shown in Table 1 . The gene expression levels were analyzed using the $2^{-\triangle \triangle \mathrm{CT}}$ method and determined relative to housekeeping gene glyceraldehyde 3-phosphate dehydrogenase (GAPDH). The fold change from control values was set at 1 -fold, and the fold change relative to the control values was obtained and used to express the change in gene expression.

\section{Western Blot Analysis}

The cells $\left(1 \times 10^{6}\right.$ cells/well $)$ were plated in 6 -well plates into 3 repeat wells for $24 \mathrm{~h}$, and then replaced with $4 \%$ serum medium containing normal (5.5 mM) or high levels of glucose $(25.5 \mathrm{mM})$ as well as with or without ALA (0.1, $0.2 \mathrm{mM}$ ) for 10 days. Subsequently, cells were rinsed twice using ice-cold
Table 1. Primers used for qRT-PCR Assay

\begin{tabular}{|c|c|}
\hline Gene & Primer Sequence ( $5^{\prime}$ to $3^{\prime}$ ) \\
\hline \multirow[t]{2}{*}{ GAPDH } & Forward: TTGTCTCCTGCGACTTCAACA \\
\hline & Reverse: GTGGTCCAGGGTTTCTTACTCC \\
\hline \multirow[t]{2}{*}{ COL-I } & Forward: GCATGGCCAAGAAGACATCC \\
\hline & Reverse: CCTCGGGTTTCCACGTCTC \\
\hline \multirow[t]{2}{*}{ BMP-2 } & Forward: TAAGGATTAGCAGGTCTTTG \\
\hline & Reverse: CACAACCATGTCCTGATAAT \\
\hline \multirow[t]{2}{*}{ ALP } & Forward: GAGAGC ATGACCGATGGAT \\
\hline & Reverse: ATGTTTTGGTGGTTC AGGAGG \\
\hline \multirow[t]{2}{*}{ RUNX2 } & Forward: ACCCTTCCAGACCAGCAGCAG \\
\hline & Reverse: TTCCGTCAGCGTCAACACCA \\
\hline \multirow[t]{2}{*}{ BSP } & Forward: AATGGAGACGGCGATAGTTC \\
\hline & Reverse: GTGGAGTTGGTGCTGGTG \\
\hline \multirow[t]{2}{*}{ OCN } & Forward: GAGGGCAATAAGGTAGTGAA \\
\hline & Reverse: CCATAGATGCGTTTGTAGGC \\
\hline
\end{tabular}

PBS and scraped on ice into RIPA lysis buffer. The protein was collected by centrifugation (12,000 rpm) at $4^{\circ} \mathrm{C}$ for 15 minutes. Protein samples were separated with $15 \%$ sodium dodecyl sulfate-polyacrylamide gel electrophoresis gel for 2 hours and transferred onto a polyvinylidene difluoride membrane (Millipore Corp., Bedford, MA, USA). After blocking non-specific-binding sites with $5 \%$ nonfat milk for 60 minutes at room temperature, the membranes were incubated overnight at $4{ }^{\circ} \mathrm{C}$ with a primary monoclonal antibody against p-Akt (Ser473) at 1:2000 dilution or Aktat 1:1000 dilution (Cell Signaling Technology, Beverly, MA, USA), followed by horseradish peroxidase-conjugated goat antirabbit IgG secondary antibody (Cell Signaling Technology) at 1:5000 dilution for 60 minutes at room temperature after being washed 3 times with TBST for 10 minutes each. The membranes were then washed 3 times with TBST and the immunoreactive bands were visualized using a chemiluminescence (ECL) kit (Biomiga, Inc., San Diego, CA, USA). The intensity of the protein bands was quantified by densitometric scanning using Image software and normalized to GAPDH (Zhong Shan-Golden Bridge Technology Inc., Beijing, China).

\section{Statistical analysis}

All statistical analyses were performed using the SPSS 17.0 statistical software. Data were expressed as the means \pm standard deviation (SD). Statistical analyses were carried out using one-way ANOVA and Student's t test. Differences between groups were considered significant at $P<0.05$.

\section{Results}

Cell viability

High glucose inhibits osteoblast proliferation but this effect is reversed by treatment with ALA. As shown in Fig. 1A, the number of cells in the control (NG) group was increased gradually from days 3 to 10 , but the rate of rise was slowdown from days 10 to 14 . However, the HG group exhibited significantly lower growing cells than the control group $(P<0.01)$, and the cells present negative growth from days 10 to 14 . ALA $(0.1,0.2 \mathrm{mM})$ significantly increased the survival of MC3T3-E1 cells in a dose-dependent manner (vs. HG group, $P<$ 0.01).

ROS and Superoxide Dismutase (SOD) production

ALA inhibits high glucose-induced ROS production and meanwhile stimulates the SOD production. Results showed that high glucose resulted in a marked increase in intracellular ROS production in MC3T3-E1 cells (vs. Control, $P<0.01$ ); however, ALA $(0.1,0.2 \mathrm{mM}$ ) 
Fig. 1. Effects of high glucose and ALA on the proliferation, oxidative stress and osteogenic differentiation of MC3T3-E1 cells. (A) MTT assays. (B) ROS level. (C) SOD level. (D) Serum ALP expression. ROS: reactive oxygen species; SOD: superoxide dismutase. NG: normal glucose (5.5 mM) $\alpha$-MEM alone, defined as control group; $\mathrm{HG}$ : high glucose (25.5 mM) $\alpha$-MEM alone; $\mathrm{HG}+$ : high glucose $\alpha$-MsEM $+0.1 \mathrm{Mm}$ ALA; HG++: high glucose $\alpha$-MEM $+0.2 \mathrm{Mm} \mathrm{ALA} .{ }^{*} \mathrm{P}<0.05$ and ${ }^{* *} \mathrm{P}$ $<0.01$ compared to the NG group; \# $\mathrm{P}<0.05$ and ${ }^{\# \#} \mathrm{P}<0.01$ compared to the HG group.

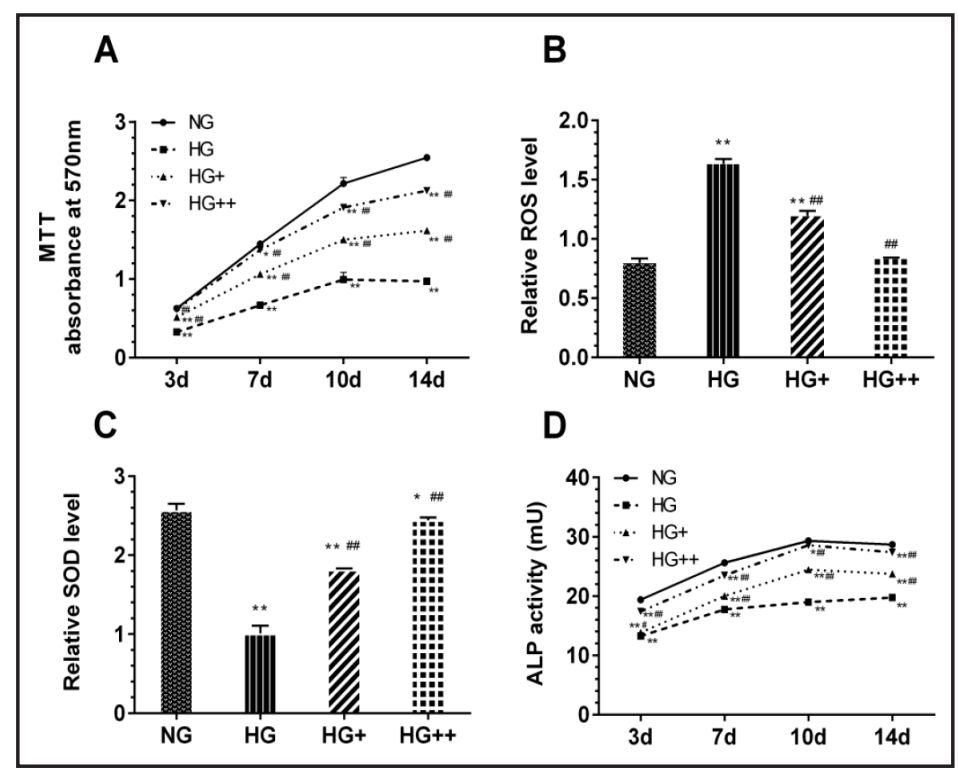

Fig. 2. Effects of high glucose and ALA on the mineralization of MC3T3-E1 cells. (A) Alizarin red staining result of NG group. (B) Alizarin red staining result of HG group. (C) Alizarin red staining result of $\mathrm{HG}+$ group. (D) Alizarin red staining result of $\mathrm{HG}++$ group. ${ }^{*} \mathrm{P}<0.05$ and ${ }^{* *} \mathrm{P}<0.01$ compared to the NG group; $\mathrm{P}<0.05$ and ${ }^{\# \#} \mathrm{P}<0.01$ compared to the HG group.

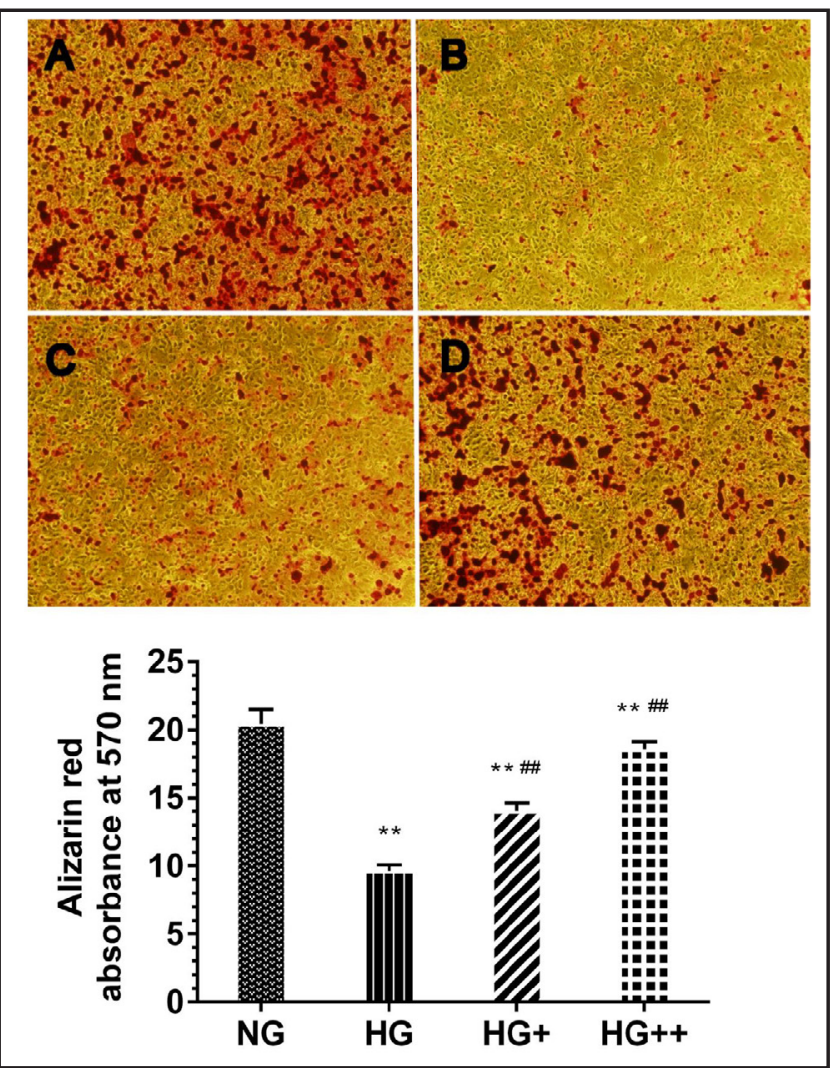

significantly reduced intracellular ROS production compared to the HG group $(P<0.01)$, as shown in Fig. 1B. Oxidative stress induced by high-glucose was marked by decreased the expression of the anti-oxidative defense enzyme of SOD (Fig. 1C, vs. Control, $P<0.01$ ). However, treatment with ALA significantly reversed the effects of high-glucose (vs. HG group, $P<0.01)$.

\section{ALP activity}

The effect of ALA on the activity of ALP, one of the representative markers for an early stage of osteoblastic differentiation, was investigated. As shown in Fig. 1D, the ALP activity 
Fig. 3. Effects of high glucose and ALA on the osteoblastic genes expression of MC3T3-E1 cells. (A) COL-I: collagen type I; (B) BMP-2: bone morphogenetic protein 2; (C) ALP: alkaline phosphatase; (D) Runx2: runt-related transcription factor 2; (E) BSP: bone sialoprotein; (F) OCN: osteocalcin. ${ }^{*} \mathrm{P}<0.05$ and ${ }^{* *} \mathrm{P}$ $<0.01$ compared to the NG group; ${ }^{*} \mathrm{P}<$ 0.05 and ${ }^{\# \# P}<0.01$ compared to the HG group.

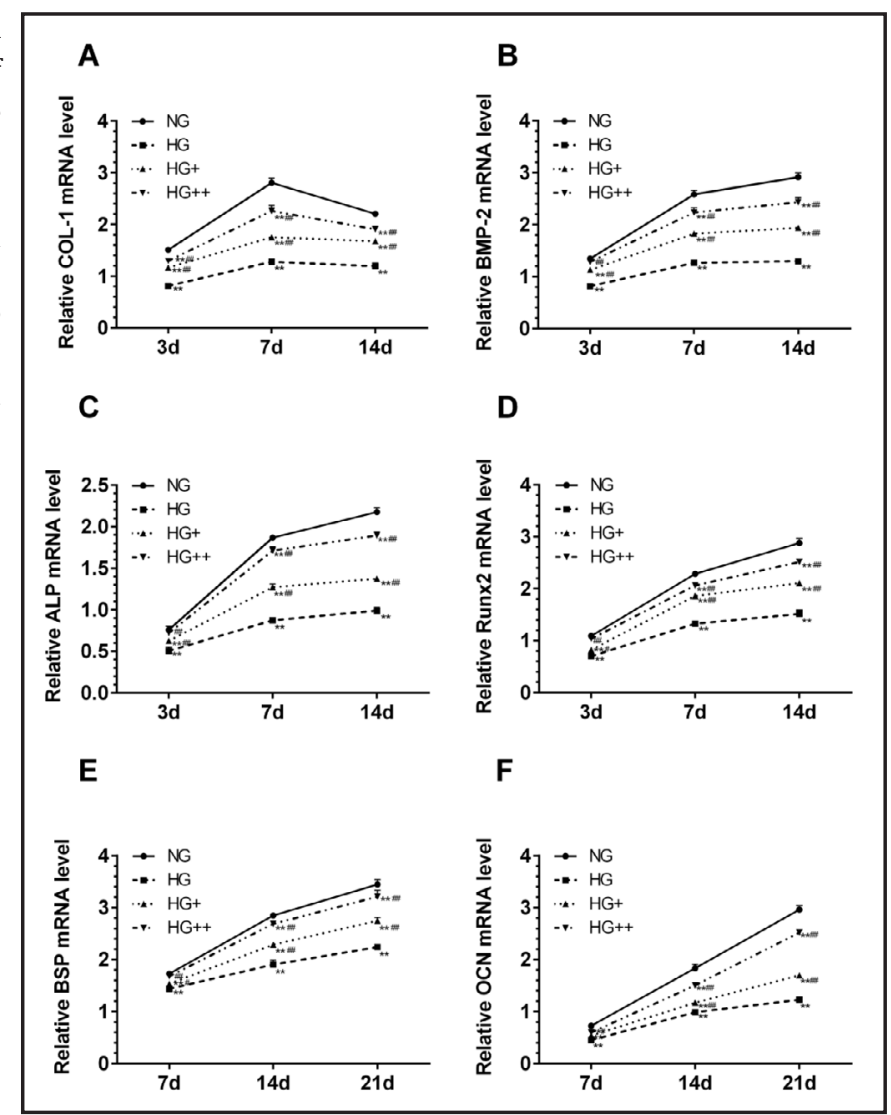

was significantly decreased in the HG group (vs. Control, $P<0.01$ ). The presence of ALA greatly increased ALP activity in a dose-dependent manner (vs. HG group, $P<0.05$ and $P<$ 0.01). Moreover, the top value of ALP activity in the control group appears at 10 days, which was postponed by high glucose.

\section{Mineralization assay}

High glucose inhibits mineralization but these effects are reversed by treatment with ALA. As shown in Fig. 2, both the images and the quantification of the Alizarin red staining demonstrated that high glucose significantly inhibited the formation of mineralized nodules in MC3T3-E1 cells (vs. Control, $P<0.01$ ) . However, $M C 3 T 3-E 1$ cells exhibited an increase in nodules after exposure to ALA (vs. HG group, $P<0.01$ ).

\section{Osteogenic genes expression}

Results revealed that high-glucose inhibited the expression of osteogenic markers in MC3T3-E1 cells (vs. Control, $P<0.01$ ), but the mRNA expression levels of all these genes markedly increased compared to HG group $(P<0.05, P<0.01)$ after treatment with ALA. Moreover, as shown in Fig. 3A, the mRNA expression of COL-1 in the control group reached the top value at 7 days, which was postponed in HG group, however, ALA accelerated the peak time of COL-1 mRNA expression. In addition, the mRNA expression levels of BMP-2, ALP, Runx2 (from days 3 to 7) and BSP (from days 7 to 14) were gradually increased, but the growth rates were slowdown respectively from days 7 to 14 and from days 14 to 21 (Fig. 3BE). The OCN mRNA expression was accelerated increased from days 7 to 21 (Fig. 3F).

\section{Effect of ALA on PI3K/Akt pathway}

The results of the Western blot analysis showed high-glucose markedly suppressed P-Akt expression levels compared to that of the control group (Fig. 4A, $P<0.01$ ). A significantly enhancement of P-Akt expression levels (vs. HG group, $P<0.01$ ) was observed 
Fig. 4. Effects of ALA on PI3K/Akt pathway. (A) Protein levels of p-Akt were determined. (B) Cells were pretreated with $10 \mathrm{mM}$ of Akt inhibitor (LY294002) for $24 \mathrm{~h}$ and the mRNA level of ALP was determined at 10 d. ${ }^{*} \mathrm{P}<0.05$ and ${ }^{* *} \mathrm{P}<0.01$ compared to the NG group; $" \mathrm{P}<0.05$ and ${ }^{\# \#} \mathrm{P}<0.01$ compared to the HG group. ${ }^{\& \&} \mathrm{P}<0.01$ compared to the $\mathrm{HG}++$ group.

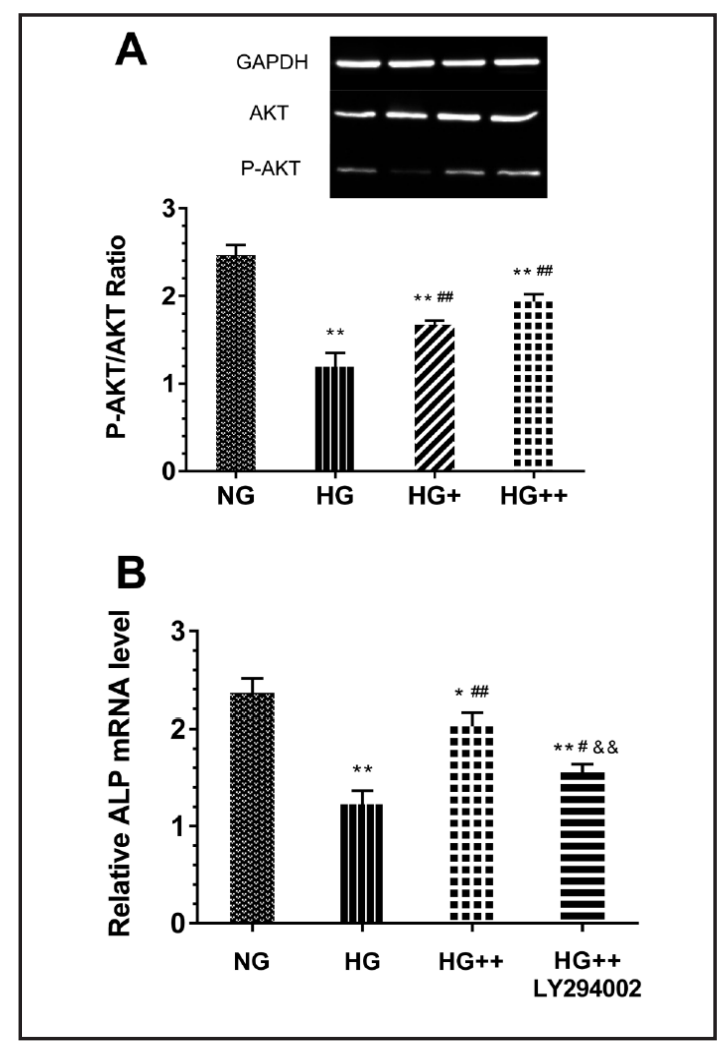

after treatment with ALA in a dose-dependent manner. To assay the association between PI3K/Akt signaling and ALA-induced osteogenic differentiation of MC3T3-E1 cells, cells were pretreated with $10 \mathrm{mM}$ of Akt inhibitor (LY294002, Sigma) before ALA (0.2mM). We found that the increased expression of ALP mRNA induced by ALA was significantly attenuated by addition of LY294002 (Fig. 4B, $P<0.01$ ).

\section{Discussion}

Bone healing around titanium implants and at fracture sites is recognized to follow a sequential and overlapping series of events [21]. On placement of the implant into the prepared alveolar socket, haemostasis and clot formation are followed by the recruitment of inflammatory cells to the wound site, collectively providing the source of growth factors, cytokines and chemokines. The signaling milieu promotes the wound healing events associated with fibrolysis and the migration of mesenchymal cells to the site to synthesis a loose connective tissue capable of supporting angiogenesis. Undifferentiated mesenchymal cells migrate into the site, attach, proliferate and differentiate down osteogenic lineages, which were then differentiate into osteoblasts in the foetal connective tissue matrix, followed by initiate bone matrix formation and mineralization.

Hyperglycemia associated with diabetes has been proved to be responsible for delayed bone healing, and it has the potential to affect a number of stages in the bone healing process, such as vascularization, clot formation, and bone matrix synthesis [22]. Researches $[23,24]$ have reported that hyperglycaemia reduce the rate of bone formation markers including osteocalcin, bone-specific alkaline phosphatase (bALP) and procollagen type 1 Nterminal propeptide (PINP). Our studies also have demonstrated that high-glucose significantly inhibited the proliferation, osteogenic differentiation, and mineralization of MC3T3-E1 cells. One major cause may be related by the over-production of reactive oxygen species (ROS) induced by hyperglycemia, which subsequently disrupts the cellular oxidant/ antioxidant balance $[25,26]$. Our studies have yielded the same conclusion that high-glucose 


\section{Cellular Physiology Cell Physiol Biochem 2017;42:1897-1906 \\ \begin{tabular}{l|l|l} 
DOI: 10.1159/000479605 & and Biochemistry 2017 Published online: August 03, 2017 & $\begin{array}{l}\text { O 2017 Tuthor(s). Published by S. Karger AG, Basel } \\
\text { www.karger.com/cpb }\end{array}$
\end{tabular}}

Dong et al.: ALA Promotes Osteogenesis of MC3T3-E1 Cells

significantly promoted the production of ROS and meanwhile observably down-regulated the anti-oxidative defense enzyme of SOD.

ROS consist of oxygen free radicals and other chemical entities such as superoxide free radicals, hydrogen peroxide, singlet oxygen, nitric oxide (NO), and peroxynitrite [27]. It is now widely accepted that ROS can cause severe damage to DNA, proteins, and lipids. ROS can lead to a reduction of cell proliferation, apoptosis, cell cycle arrest, and modulation of differentiation [28]. Concerning bone metabolism, in vitro studies have shown that oxidative stress inhibits osteoblastic differentiation and induces osteoblast insults and apoptosis [29, 30]. Thus, oxidative stress may be related to the pathogenesis of diabetic bone disorder. In line with above researches, our experiments showed that the viability of cells was significantly inhibited by high-glucose, and presented negative growth from days 10 to 14 . And also, the ALP activity and the COL-1 mRNA expression were greatly decreased in the HG group, and the peck times of both were postponed by high glucose, indicating that the osteogenic differentiation and bone matrix formation were inhibited by the high-glucose. Moreover, the mineralization nodules and the mRNA expression levels of BMP-2, ALP, Runx2, BSP and OCN were also significantly down-regulated by high-glucose, indicating that highglucose restrained the osteogenic mineralization process.

Alpha-lipoic acid (ALA) attenuates bone loss by quenching oxidative stress. The potency of ALA for scavenging certain ROS and peroxynitrite and mitigating inflammationinduced bone loss has been demonstrated in several models [31]. Radzki et al. [32] used an ovariectomized rat model showed that ALA applied to the ovariectomized rats in the dose of $50 \mathrm{mg} / \mathrm{kg}$ not only stopped the bone resorption, but stimulated its formation. Cell culture studies suggest that [33] media supplementation with ALA $(0.1-1 \mathrm{mM})$ can protect osteoblasts from the damaging effect of extracellular ROS by restoring endogenous antioxidant defences and raised alkaline phosphatase activity, meanwhile up-regulated key genes involved in bone mineralization, i.e., collagen type-I and osteocalcin. The exact regulatory mechanism of ALA on these genes is currently unknown; however, available evidence suggests that the ROS scavenging properties of ALA/DHLA may be critically important [34]. Similar with above results, our experiments shows that the increased ROS and decreased SOD production induced by high-glucose were significantly reversed by ALA $(0.1,0.2 \mathrm{mM})$ treatment. Meanwhile, the proliferation, osteogenic differentiation, and mineralization of MC3T3-E1 cells were obviously promoted by ALA in a dose-dependent manner. Therefore, our studies demonstrated that ALA attenuates the adverse effect of ROS induced by high-glucose on MC3T3-E1 cells.

The biological behavior of osteoblasts is closely connection with the cell signaling pathways. Among them, the PI3K/AKT signaling pathway plays an important role on the proliferation and mineralization of osteoblasts [35]. PI3K is a heterodimeric enzyme important for proliferation and apoptosis, while Akt is a downstream serine-threonine kinase that transmits survival signals from growth factors [36]. The PI3K/AKT signaling pathway is the major effector of metabolic insulin action, which is involved in several fundamental cellular processes, including cell proliferation, mineralization, gluconeogenesis, glycogen synthesis and so on [37]. Kawamura et al. [38] reported that PI3K/Akt pathway and its downstream targets are critical regulators of bone resorption and bone formation. In this study, we found that high-glucose significantly inhibited the expression level of P-Akt compared to the control group. However, ALA reversed the negative effect of highglucose. Also we found that ALA increased expressions of ALP mRNA in HG group, however, pretreatment with LY294002 could eliminate positive effects of ALA, suggesting that ALA promotes oeteogenic differentiation of MC3T3-E1 cells under high-glucose condition partly by modulation of PI3K/Akt pathway.

In conclusion, the findings of our study demonstrated that ALA inhibited high glucose induced ROS production and stimulated proliferation, differentiation and mineralization of MC3T3-E1 cells through the modulation of PI3K/Akt pathway. However, the in vitro studies cannot mimic in vivo conditions. Therefore, further researches are required to clarify the in vivo actions and mechanisms. 


\section{Cellular Physiology Cell Physiol Biochem 2017;42:1897-1906

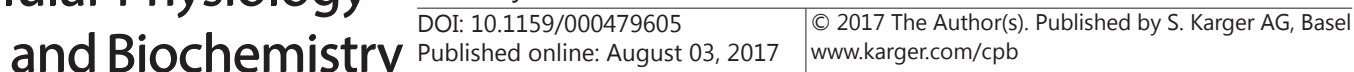 \\ Dong et al.: ALA Promotes Osteogenesis of MC3T3-E1 Cells}

\section{Foundation}

This paper belongs to the science and technology plan project of Yantai (NO.2015WS065).

\section{Disclosure Statement}

The authors declare no conflict of interest.

\section{References}

1 Tomasi C, Wennstrom JL, Berglundh T: Longevity of teeth and implants - a systematic review. J Oral Rehabil 2008;35:S23-32.

$\longrightarrow 2$ Branemark PI, Adell R, Breine U, Hansson BO, Lindstrom J, Ohlsson A: Intra-osseous anchorage of dental prostheses. I. Experimental studies. Scand J Plast Reconstr Surg 1969;3:81-100.

3 Marx RE, Garg AK: Bone structure, metabolism, and physiology: its impact on dental implantology. Implant Dent 1998;7:267-276.

4 Pjetursson BE, Bragger U, Lang NP, Zwahlen M: Comparison of survival and complication rates of toothsupported fixed dental prostheses (FDPs) and implant-supported FDPs and single crowns (SCs). Clin Oral Implants Res 2007;18:S97-113.

5 Jung RE, Pjetursson BE, Glauser R, Zembic A, Zwahlen M, Lang NP: A systematic review of the 5-year survival and complication rates of implant-supported single crowns. Clin Oral Implants Res 2008;19:119130.

6 Mellado-Valero A, Ferrer Garcia JC, Herrera Ballester A, Labaig Rueda C: Effects of diabetes on the osseointegration of dental implants. Med Oral Patol Oral Cir Bucal 2007;12:e38-43.

-7 Marchand F, Raskin A, Dionnes-Hornes A, Barry T, Dubois N, Valero R, Vialettes B: Dental implants and diabetes: conditions for success. Diabetes Metab 2012;38:14-19.

$\checkmark 8$ Wang F, Song YL, Li DH, Li CX, Wang Y, Zhang N, Wang BG: Type 2 diabetes mellitus impairs bone healing of dental implants in GK rats. Diabetes Res Clin Pract 2010;88:e7-9.

9 Berglundh T, Persson L, Klinge B: A systematic review of the incidence of biological and technical complications in implant dentistry reported in prospective longitudinal studies of at least 5 years. J Clin Periodontol 2002;29:S197-212.

10 Ajami E, Bell S, Liddell RS, Davies JE: Early bone anchorage to micro- and nano-topographically complex implant surfaces in hyperglycemia. Acta Biomater 2016;39:169-179.

-11 Waddington RJ, Alraies A, Colombo JS, Sloan AJ, Okazaki J, Moseley R: Characterization of oxidative stress status during diabetic bone healing. Cells Tissues Organs 2011;194:307-312.

12 King S, Klineberg I, Levinger I, Brennan-Speranza TC: The effect of hyperglycaemia on osseointegration: a review of animal models of diabetes mellitus and titanium implant placement. Arch Osteoporos 2016;11:29.

13 Hamada Y, Fujii H, Fukagawa M: Role of oxidative stress in diabetic bone disorder. Bone 2009;45:S35-38.

-14 Nagesh Babu G, Kumar A, Singh RL: Chronic pretreatment with acetyl-L-carnitine and +/-DL-alpha-lipoic acid protects against acute glutamate-induced neurotoxicity in rat brain by altering mitochondrial function. Neurotox Res 2011;19:319-329.

15 Aydin A, Halici Z, Akoz A, Karaman A, Ferah I, Bayir Y, Aksakal AM, Akpinar E, Selli J, Kovaci H: Treatment with alpha-lipoic acid enhances the bone healing after femoral fracture model of rats. Naunyn Schmiedebergs Arch Pharmacol 2014;387:1025-1036.

-16 von Wilmowsky C, Schlegel KA, Baran C, Nkenke E, Neukam FW, Moest T: Peri-implant defect regeneration in the diabetic pig: A preclinical study. J Craniomaxillofac Surg 2016;44:827-834.

17 Polat B, Halici Z, Cadirci E, Albayrak A, Karakus E, Bayir Y, Bilen H, Sahin A, Yuksel TN: The effect of alphalipoic acid in ovariectomy and inflammation-mediated osteoporosis on the skeletal status of rat bone. Eur J Pharmacol 2013;718:469-474. 


\section{Cellular Physiology Cell Physiol Biochem 2017;42:1897-1906 \begin{tabular}{l|l|l} 
and Biochemistry Published onlIne: August 03, 2017 & $\begin{array}{l}\text { C) } 2017 \text { The Author(s). Published by S. Karger AG, Basel } \\
\text { www.karger.com/cpb }\end{array}$ \\
\hline
\end{tabular}}

Dong et al.: ALA Promotes Osteogenesis of MC3T3-E1 Cells

18 Quarles LD, Yohay DA, Lever LW, Caton R, Wenstrup RJ: Distinct proliferative and differentiated stages of murine MC3T3-E1 cells in culture: an in vitro model of osteoblast development. J Bone Miner Res 1992; 7:683-692.

19 Fu C, Xu D, Wang CY, Jin Y, Liu Q, Meng Q, Liu KX, Sun HJ, Liu MZ: Alpha-Lipoic Acid Promotes Osteoblastic Formation in H2O2 -Treated MC3T3-E1 Cells and Prevents Bone Loss in Ovariectomized Rats. J Cell Physiol 2015;230:2184-2201.

-20 Garcia-Hernandez A, Arzate H, Gil-Chavarria I, Rojo R, Moreno-Fierros L: High glucose concentrations alter the biomineralization process in human osteoblastic cells. Bone 2012;50:276-288.

21 Davies JE: Understanding peri-implant endosseous healing. J Dent Educ 2003;67:932-949.

-22 Sardina JL, Lopez-Ruano G, Sanchez-Sanchez B, Llanillo M, Hernandez-Hernandez A: Reactive oxygen species: are they important for haematopoiesis? Crit Rev Oncol Hematol 2012;81:257-274.

-23 Kanazawa I, Yamaguchi T, Yamamoto M, Yamauchi M, Kurioka S, Yano S, Sugimoto T: Serum osteocalcin level is associated with glucose metabolism and atherosclerosis parameters in type 2 diabetes mellitus. J Clin Endocrinol Metab 2009;94:45-49.

24 Shu A, Yin MT, Stein E, Cremers S, Dworakowski E, Ives R, Rubin MR: Bone structure and turnover in type 2 diabetes mellitus. Osteoporos Int 2012;23:635-641.

25 Xiao WL, Zhang DZ, Fan CH, Yu BJ: Intermittent Stretching and Osteogenic Differentiation of Bone Marrow Derived Mesenchymal Stem Cells via the p38MAPK-Osterix Signaling Pathway. Cell Physiol Biochem 2015;36:1015-1025.

-26 Bellin C, de Wiza DH, Wiernsperger NF, Rosen P: Generation of reactive oxygen species by endothelial and smooth muscle cells: influence of hyperglycemia and metformin. Horm Metab Res 2006;38:732-739.

27 Chong ZZ, Li F, Maiese K: Oxidative stress in the brain: novel cellular targets that govern survival during neurodegenerative disease. Prog Neurobiol 2005;75:207-246.

28 Bai XC, Lu D, Bai J, Zheng H, Ke ZY, Li XM, Luo SQ: Oxidative stress inhibits osteoblastic differentiation of bone cells by ERK and NF-kappaB. Biochem Biophys Res Commun 2004;314:197-207.

29 Zhou N, Hu N, Liao JY, Lin LB, Zhao C, Si WK, Yang Z, Yi SX, Fan TX, Bao W, Liang X, Wei X, Chen H, Chen C, Chen Q Lin X, Huang W: HIF-1alpha as a Regulator of BMP2-Induced Chondrogenic Differentiation, Osteogenic Differentiation, and Endochondral Ossification in Stem Cells. Cell Physiol Biochem 2015;36:4460.

30 Fatokun AA, Stone TW, Smith RA: Hydrogen peroxide-induced oxidative stress in MC3T3-E1 cells: The effects of glutamate and protection by purines. Bone 2006;39:542-551.

-31 Kondo H, Takeuchi S, Togari A: beta-Adrenergic signaling stimulates osteoclastogenesis via reactive oxygen species. Am J Physiol Endocrinol Metab 2013;304:e507-515.

-32 Radzki RP, Bienko M, Wolski D, Lis A, Radzka A: Lipoic acid stimulates bone formation in ovariectomized rats in a dose-dependent manner. Can J Physiol Pharmacol 2016;94:947-954.

33 Cui J, Xiao Y, Shi YH, Wang B, Le GW: Lipoic acid attenuates high-fat-diet-induced oxidative stress and B-cell-related immune depression. Nutrition 2012;28:275-280.

-34 Xiao Y, Cui J, Shi Y, Le G: Lipoic acid increases the expression of genes involved in bone formation in mice fed a high-fat diet. Nutr Res 2011;31:309-317.

-35 Schultze SM, Hemmings BA, Niessen M, Tschopp 0: PI3K/AKT, MAPK and AMPK signalling: protein kinases in glucose homeostasis. Expert Rev Mol Med 2012;14:e1.

-36 Leavens KF, Easton RM, Shulman GI, Previs SF, Birnbaum MJ: Akt2 is required for hepatic lipid accumulation in models of insulin resistance. Cell Metab 2009;10:405-418.

-37 Du K, Herzig S, Kulkarni RN, Montminy M: TRB3: a tribbles homolog that inhibits Akt/PKB activation by insulin in liver. Science 2003;300:1574-1577.

-38 Kawamura N, Kugimiya F, Oshima Y, Ohba S, Ikeda T, Saito T, Shinoda Y, Kawasaki Y, Ogata N, Hoshi K, Akiyama T, Chen WS, Hay N, Tobe K, Kadowaki T, Azuma Y, Tanaka S, Nakamura K, Chung UI, Kawaguchi H: Akt1 in osteoblasts and osteoclasts controls bone remodeling. PLoS One 2007;2:e1058. 